\title{
Gênero, sexualidade e experimentação de si em plataformas digitais on-line
}

\author{
Gender, sexuality and self-experimentation in \\ on-line digital platforms
}

(1) Débora Krischke Leitão*

(1) Laura Graziela Gomes**

\begin{abstract}
Resumo: Esse trabalho parte de pesquisa realizada em um mundo virtual 3D e outras plataformas digitais, para refletir sobre novas formas de experimentação de si, presentes nas mídias digitais contemporâneas. Enfatizamos usos e apropriações criativas dessas plataformas em experimentações de gênero e sexualidade, propomos pensar nessas tecnologias como agenciadoras de novos processos de subjetivação.

Palavras-chave: Internet. Gênero. Experimentação de si.

Abstract: This work is based on a research conducted in a 3D virtual world and other digital platforms to discuss new forms of self-experimentation in contemporary digital media. We emphasize the creative uses and appropriations of these platforms in gender and sexuality experimentations and we propose to think of these technologies as agents of new processes of subjectivation.
\end{abstract}

Keywords: Internet. Gender. Self-experimentation.

A partir das pesquisas que realizamos nos últimos anos em plataformas digitais em interfaces $2 \mathrm{D}$ e $3 \mathrm{D}$, procuramos discutir como estas estão sendo apropriadas taticamente para construções e desconstruções no que concerne a gênero e sexualidades, ao mesmo tempo em que produzem outras possibilidades e arranjos de tais categorias. Compreendendo, como sugere Hine (2000), a internet como artefato cultural além de contexto, trazemos para o centro

\footnotetext{
*Doutora em Antropologia Social pela Universidade Federal do Rio Grande do Sul (Ufrgs, Porto Alegre, RS, Brasil), professora do PPG em Ciências Sociais da UFSM em Santa Maria, RS, Brasil<deborakl@gmail.com>.

**Doutora em Antropologia pela Universidade de São Paulo (USP, São Paulo, SP, Brasil), professora do PPG em Antropologia da UFF no Rio de Janeiro, RJ, Brasil <lauragraziela@ gmail.com>.
} 
de nossa reflexão as particularidades sociotécnicas das plataformas por nós estudadas. Em seu trabalho mais recente, Hine (2015) também sugere que, com a ampliação de acesso, a internet tornou-se mais "familiar" e "amigável", de modo que muitas vezes sua estrutura e seus modos de funcionamento passem desapercebidos pelos usuários em seu uso cotidiano. Enquanto pesquisadoras, no entanto, não podemos deixar de atentar para a estrutura das plataformas digitais, tanto em termos de software quanto de hardware. Concordando com tal perspectiva, tomamos as mídias digitais como ambientes propiciadores de determinadas experiências, dotadas de capacidades de agenciamento, e não apenas um meio ou local onde algo acontece.

Embora nossa reflexão parta de nossas etnografias no mundo virtual 3D Second Life (SL), nesse trabalho, não nos restringimos a ele, incorporando reflexões, que são fruto de deslocamentos para outras plataformas, como facebook, fetlife, flickr, tumblr, youtube, tanto perseguindo os rastros das trajetórias de interlocutores na web, quanto tentando, a partir das outras plataformas, desenvolver um olhar comparativo sobre dinâmicas semelhantes às que pesquisamos no SL.

Nossa proposta, nesse trabalho, é pensar as plataformas digitais, não só como espaços públicos importantes de visibilização LGBTQI, ${ }^{1}$ mas, igualmente, transformando-se em laboratórios, ambientes que permitem a experimentação de si, o que inclui experimentações de gênero e sexualidade. Para tanto, iniciamos com uma breve reflexão sobre a relação dos residentes do Second Life com os próprios avatares, apontando para processos de subjetivação associados às práticas de criação de avatares alternativos. A seguir, discutimos experimentações que dizem respeito mais especificamente a gênero e sexualidade nesse ambiente, relacionando-as a dinâmicas semelhantes, identificadas em outras plataformas digitais. Por último, propomos um debate sobre transgeneridade e mídias digitais, argumentando que tais plataformas, para além de serem meros espaços de visibilização de grupos e/ ou indivíduos trans, ativamente agenciam novos regimes de self e identidades transgêneras.

\footnotetext{
${ }^{1}$ Optamos nesse artigo pela sigla LGBTQI por acreditarmos ser mais abrangente e englobadora das experiências de nossos/as interlocutores/as de pesquisa, considerando os desdobramentos das novas identidades e dos próprios movimentos internos que elas geram, por exemplo outras identidades trans em jogo que não as transgeneridades binárias, como agêneros, fluídos e nãobinários. Também ressaltamos que grande parte de nossos/as interlocutores/as de pesquisa não residem no Brasil, a língua de comunicação não é o português, mas o inglês, e estabelecem diálogo muitas vezes com o contexto norte-americano no qual o ativismo queer tem maior protagonismo.
} 


\section{Das multidões em nós}

A pesquisa que deu origem a esse artigo tem como campo empírico principal um mundo virtual 3D, chamado Second Life, no qual realizamos etnografias desde 2007. Esse mundo virtual foi criado pela empresa norteamericana Linden Lab, e aberto ao público em 2003. Uma das características de um mundo virtual 3D, conforme já mostramos em outros trabalhos (Gomes e Leitão, 2013), é o fato de seus usuários serem nele representados por meio de avatares, sendo essa corporificação do usuário no avatar, condição essencial para a vivência da imersão, principal diferencial desses ambientes.

Autores que vêm realizando pesquisas e reflexões teóricas sobre os usos da internet, contemporaneamente, têm mostrado que, a cada dia nos afastamos mais de uma realidade empírica, na qual on e off, virtual e real, se opõem como polos separados e qualitativamente diferenciados. Os próprios conceitos de "cibercultura" ou "ciberespaço", tão frequentes na produção das Ciências Sociais do final da década de 90 e início dos anos 2000 (Escobar, 1994), que coincidiram com o boom da internet comercial, foram sendo substituídos por perspectivas que conferem centralidade ao digital, em detrimento do "ciber". Assim, é mais comum que hoje se fale em uma antropologia digital (Miller e Horst, 2012) ou sociologia digital (Lupton, 2015; Miskolci, 2016). A ampliação do acesso, sobretudo a partir de tecnologias móveis e relativamente mais baratas, tornou-nos permanentemente conectados.

Nesse sentido, concordamos com aqueles que enfatizam a necessidade de pensarmos on e off, não como domínios disjuntivos, mas em termos de um continuum on-line-off-line (Beleli e Miskolci, 2015). Esse continuum, no entanto, não é plano ou linear, e sua topografia é variável, de acordo com a plataforma, ou usos que determinados grupos fazem dela, o que significa que, para mapeá-lo, é necessário considerarmos, tanto os contextos locais ou particulares de uso, quanto os agenciamentos (maquínicos, estruturais, de software, algorítmicos) propiciados pelas diferentes plataformas. Em um trabalho anterior (Gomes e Leitão, 2013), já apontamos para essa posição e suas consequências em termos da pesquisa etnográfica.

No caso do Second Life, nos deparamos com um horizonte no qual as dinâmicas on-line/off-line operam de modos muito distintos daquelas de outras plataformas, à semelhança de redes sociais como o Facebook, Twitter, ou aplicativos de buscas amorosas. A questão do anonimato e de certa independência, conferida aos avatares pelos residentes do SL, não pode ser menosprezada. A própria noção de que sua vivência naquele espaço configura 
um tipo de "residência", uma existência em outro lugar, e não um uso, já que não nomeiam a si mesmos como "usuários" ou "jogadores", pode ser referida como um primeiro indício dessa diferença. Mais além, a distinção êmica entre real life (RL) e second life (SL) é transversal aos diferentes ambientes de sociabilidade desse mundo virtual 3D. Embora percebamos, em nossas pesquisas, que essas fronteiras estejam, na prática, sujeitas a uma série de deslizamentos, sendo mais ou menos rígidas, dependendo do grau de proximidade entre as pessoas, o tempo de convívio, ou o tipo de atividade que ali desempenham, na vida cotidiana do SL, elas são levadas a sério. É comum ouvirmos, nesse mundo virtual 3D, comentários como "SL é SL e RL é RL", "Eu não misturo RL com SL", "o que acontece no SL fica no SL" ou ainda "RL sempre vem em primeiro lugar", e transpassar essas fronteiras, a menos que seja convidado a fazê-lo, é considerado desrespeitoso e um desconhecimento da etiqueta e lógicas locais. Essa diferença com relação a outras plataformas não é irrelevante e, certamente, é um dos pontos que possibilita sua riqueza como espaço de experimentação de si, em termos de gênero, sexualidade e outros modos de existência.

A discussão sobre experimentações de gênero e sexualidade, embora não fosse, de início, nossa preocupação central de pesquisa, foi, aos poucos, se impondo como questão durante o trabalho de campo. Isso ocorreu quando tomamos como objeto de pesquisa os vínculos e afetos envolvidos nas relações dos usuários com seus próprios avatares, ao invés de entendê-los apenas como "substitutos" ou "extensões" dos primeiros, ou seja, como um dos aspectos da conectividade, imersividade e sociabilidade entre humanos no SL. Ainda que todas as interações entre diferentes avatares e igualmente entre diferentes usuários sejam muito importantes, o engajamento do usuário com seu próprio avatar deixou evidente o quanto o problema da identidade perpassa todas as situações naquele ambiente digital.

Experiências e observações anteriores mostraram que a participação de usuários em diferentes plataformas digitais, com seus perfis de avatares do Second Life ou de personagens de suas séries preferidas, filmes, games, animes, $H Q s$, ou, ainda, celebridades, não somente leva a formas distintas de engajamento, mas implica um investimento na produção de subjetividades igualmente distintas, fazendo com que a identidade da pessoa que administra todas aquelas contas/perfis seja experimentada de forma fraturada, dispersa, cada vez menos auto evidente, menos totalizada, ao contrário do que ocorre quando temos perfis construídos a partir da identidade civil do usuário e nos deparamos com representações de sujeitos autorregulados, unificados, coerentes e autocentrados. 
Ao longo dos anos de pesquisa no SL, percebemos que a maioria de nossos interlocutores tinha mais de um avatar registrado na plataforma. Esses avatares são referidos pela categoria "alt", avatar alternativo, e mesmo que muitas vezes sua existência não seja segredo para amigos do residente que os criou e mantém, é comum que cada um desses avatares tenha uma biografia própria, seja mais voltado para uma atividade ou círculo social, e apresente aparência singular. Ouvimos de alguns interlocutores relatos sobre considerarem seu primeiro avatar registrado no SL como seu avatar principal, supostamente mais próximo de suas vidas off-line ou correspondendo mais a suas identidades "analógicas", sendo os demais considerados avatares alternativos. Muitos desses residentes frequentam há mais de uma década o mundo virtual, e percebemos que, embora o discurso oficial seja de ser o primeiro aquele que é considerado o avatar principal, na prática, um ou outro de seus avatares adquirirem centralidade em determinados momentos de suas vidas on-line, tornando-se uma espécie de "avatar principal" temporário.

Como pesquisadoras da e na rede, constatamos que, na maior parte das vezes, usuários nunca conseguem ser inteiramente fiéis ou coerentes com suas próprias representações de si e acabam produzindo "lateralidades" ou "dobras" (Rose, 2011). Assim, em alguns casos, a circulação entre os avatares alternativos é ainda mais potencializada, e cada um deles adquire uma centralidade circunstancial e relacionada a práticas específicas: atividades comerciais, artísticas, de trabalho, ou frequência a locais dedicados a determinadas práticas sexuais.

Num ambiente on-line bastante mais popular e menos exótico, Parreiras (2008) descreveu dinâmicas semelhantes de produção plural de perfis, "oficiais", "fakes" e "masks", esses últimos especificamente relacionados à experimentação identitária. No caso do $\mathrm{SL}$, a circulação entre avatares diferentes produz deslocamentos e jogos identitários, possibilitando experimentações múltiplas, e a vivência dos residentes em cada uma dessas reencarnações de pixels tem efeitos profundos. A rede e a condição de estar sempre conectado ganha enorme relevância na vida desses sujeitos, uma vez que ela é o lugar onde, afinal de contas, eles habitam e constituem um modo próprio de existência (Ingold, 2011), logo de produção de si mesmos, em suma, vindo a ser o lugar onde se constituem como sujeitos, onde costuram-se, por dentro e por fora.

\section{O on-line como laboratório}

Uma dessas possibilidades de fraturamento do self através de experimentações identitárias descritas anteriormente ocorre no SL em relação 
às questões de gênero, especialmente quando esta dimensão de si torna-se determinante para a vida dos sujeitos, ou então, quando o próprio ambiente tecnológico coloca à disposição objetos técnicos, caso dos próprios avatares, cuja agência pode suscitar questões e estimular experiências nesta direção.

Além dos mundos virtuais, em nossas experiências de pesquisa em jogos on-line encontramos dinâmicas semelhantes. Conversando com jogadores de LOL, ${ }^{2}$ por exemplo, muitos disseram que é bastante comum jogarem com avatares femininas, sem se perceberem como homossexuais ou transgêneras, e, vice-versa, que é comum também jogadoras jogarem com avatares masculinos, sem se declararem homossexuais ou transgêneros. Segundo os jogadores, isso ocorre pelo simples fato de acharem avatares femininas mais bonitas, sensuais, e, no caso das jogadoras, por acharem que avatares masculinos se impõem mais no jogo. Entretanto, jogadoras mulheres afirmam que, apesar de jogadores homens gostarem da experiência de jogarem como avatares femininas, isso não impede de serem, ao mesmo tempo, machistas e grosseiros quando jogadoras revelam sua identidade de gênero de fora do jogo. Dessa forma, não é incomum os games serem considerados ambientes onde há muita intolerância e violência de gênero.

Em experiência de pesquisa de campo no $\mathrm{MMORPG}^{3}$ World of Warcraft (WoW), que tivemos em nosso grupo de pesquisa, dados semelhantes àqueles acima descritos sobre o LOL foram produzidos. A vivência da pesquisadora dentro do jogo mostrou ser recorrente o fenômeno de criação de personagens femininas por homens. Para ampliar a compreensão do fenômeno, a pesquisa estendeu-se para além do ambiente do jogo, e foi usado, também, o fórum oficial Battle.net. A pesquisadora, através de sua personagem jogadorapesquisadora Malum, criou, no fórum, um tópico de discussão com o título "Chars ${ }^{4}$ femininos, mulheres ou homens?", que teve 276 respostas, com diversas justificativas, embora todas concordassem em afirmar que a maioria dos homens tem, entre outros personagens, uma ou mais chars femininas. A maioria das respostas girava em torno de razões estéticas, conferindo às

\footnotetext{
${ }^{2}$ League of Legends: jogo on-line multiplayer, lançado em 2009 e bastante popular no Brasil contemporaneamente.

${ }^{3}$ Massively Multiplayer On-line Role-Playing Game, representado comumente pela sigla MMORPG, é um jogo de interpretação de personagens on-line e em massa para múltiplos jogadores/as, sendo o World of Warcraft um dos mais populares e com maior número de contas ativas nessa categoria. Por ser on-line, assim como por sua estrutura narrativa e mecânica, o jogo possibilita interação com outros usuários através da criação de um personagem tridimensional, um avatar.

${ }^{4}$ Abreviação do termo em inglês character, empregado para designar personagens criados pelos jogadores em jogos do estilo RPG. Termo utilizado pelos jogadores de WoW para referir-se ao seu avatar.
} 
personagens femininas atributos como beleza e sensualidade, e também de liberdade de criação e representação, já que a plataforma permite a experimentação de habitar outro corpo. Os motivos relacionados a razões estéticas não são menos generificados, pelas próprias características atribuídas às personagens femininas.

Se, como dissemos, no Second Life, a grande maioria dos usuários possui avatares alternativos, e muitos deles com gêneros diferentes de seus gêneros off-line ou reais, isso não significa que sejam transgêneros ou assumam a transgeneridade em suas vidas off-line ou reais, mas que fazem do SL um ambiente onde se permitem experimentar inúmeras identidades, ou "regimes de self", dentre elas, transgêneras, da mesma forma que outras identidades alternativas como serem/viverem ali como crianças, animais, monstros, seres híbridos, objetos etc.

Uma de nossas principais interlocutoras de pesquisa no SL é Alice, uma avatar feminina que se define como t-girl, travesti ou apenas como "uma garota", dependendo do contexto e do ambiente que frequenta no SL. Alice varia sua aparência no SL, trocando suas roupas, cabelos e maquiagem, bem como variando o tamanho de seus seios. Ela se mantém, no entanto, sempre como uma mulher negra, desde que nos conhecemos em 2013. Desde a sua chegada ao SL, Alice optou por adicionar um pênis a sua avatar feminina, e, com frequência, ela usa saias que, bastante curtas, propositalmente permitem que seu pênis seja visto pelos demais residentes. Seus parceiros sexuais no SL são mais frequentemente avatares homens, com os quais se relaciona como profissional do sexo. Algumas vezes, ela também se relaciona com outras avatares trans e, muito raramente, com avatares mulheres, que têm ou mantém genitais femininos. Alice não esconde em seu perfil que na sua RL é um homem cis-gênero, ${ }^{5}$ de cerca de 40 anos e, em nossas conversas, expressa as complexas teias que a unem a sua avatar: mais do que alguém que ela desejaria ser em sua vida fora do SL, sua avatar é, segundo Alice, uma espécie de alvo de seu desejo, alguém com quem, em sua fantasia, gostaria de relacionar-se afetiva e sexualmente. Não apenas quando está efetivamente engajada em interações íntimas com outros avatares, Alice é alvo do desejo de seu criador. De acordo com ele, muito frequentemente, percebe-se eroticamente envolvido com Alice, mesmo quando sua avatar está só, pela simples visão de seu corpo nu, ou pela manipulação deste quando está mudando suas formas, seus seios, suas pernas, suas nádegas.

\footnotetext{
${ }_{5}^{5}$ Sempre que, ao longo do texto, nos referimos a categorias de identidade de gênero de interlocutores/as de pesquisa, tratam-se de categorias êmicas, ou seja, como eles mesmos se apresentam a nós e/ou aos demais nas interações estabelecidas on-line.
} 
Alice é um exemplo, entre muitos que conhecemos no SL, de como as práticas eróticas e a relação entre os avatares, e com os avatares, são pensadas pelos residentes como um laboratório para a sexualidade. Na maioria das vezes, o desejo de engajar-se nessa exploração é absolutamente consciente e explicitado para os demais. O ambiente surge como espaço possível para testar desejos e práticas, exercitando prazeres imaginativos relacionados à sexualidade, entendidos menos como formas de "imaginar uma experiência" e sim como modos de se "experimentar uma imaginação" (Viveiros de Castro, 2002, p. 123). Tais testes da imaginação erótica flutuam entre polos mais ou menos possíveis e próximos da real life, até as fronteiras da própria realidade, quando entram nos limites daquilo que é e apenas pode ser imaginação.

Parreiras (2008) mostra-nos que a maioria dos perfis "masks" frequentadores da comunidade do Orkut por ela pesquisada nunca havia tido uma experiência homossexual off-line, e que a sociabilidade e os diálogos partilhados no grupo configuravam uma espécie de educação sentimental homoerótica, uma experimentação com o próprio desejo no meio virtual. Diversos outros trabalhos, como o de Facchini e Machado (2013) e Zilli (2007) sobre BDSM, ou a pesquisa de Miskolci (2017), tanto sobre salas de chat quanto sobre aplicativos de buscas amorosas voltadas ao público gay, mostram a importância dos grupos on-line para a associação entre sujeitos que têm em comum os mesmos desejos e práticas, mas que talvez, de outro modo, não se encontrariam. Embora Miskolci (2009) aponte para a manutenção da lógica do armário nesses espaços de segredo partilhado, é inegável que a internet ampliou o "meio" da homossexualidade, e das sexualidades ou identidades de gênero dissidentes, "para mais pessoas nas metrópoles e nos recantos do interior do país. Nesses locais, a maioria jamais quis ou pode frequentar um local [off-line] claramente gay ou lésbico" (Miskolci, 2009, p. 176).

Sem desconsiderar as devidas diferenças de escala, podemos sugerir que, tanto no caso de avatares $3 \mathrm{D}$ dos mundos virtuais, quanto no caso de perfis em redes sociais, ou em aplicativos específicos de dispositivos móveis, estamos tratando de híbridos contemporâneos humano-máquina-informação. Tais entidades de hardware e software podem ser assim tratadas como objetos técnicos, que adentram aquilo que Preciado (2014) chamaria, em oposição a uma história "natural", de uma história "artificial" da sexualidade como história da tecnologia.

Em diversos trabalhos, Vencato $(2009,2013,2015)$ também vem discutindo a importância dos grupos on-line para experimentações e construções identitárias de sujeitos em torno da experiência do crossdressing. Em artigo 
recente (Vencato, 2015), a autora descreve as dinâmicas de dois fóruns do Brazilian Crossdresser Club (BCC), sublinhando as hierarquizações por ela encontradas entre aquelas cuja prática fica restrita ao "virtual" e aquelas que estendem o crossdressing para ambientes off-line. Embora a experimentação identitária on-line revele-se fundamental, uma passagem para o real parece ser desejada, para o grupo estudado ou mesmo sinal de que se tomou a prática a sério. Como argumentamos anteriormente, no Second Life as fronteiras entre on-line e off-line costumam ser mais estritas do que em alguns outros ambientes digitais contemporâneos. É importante salientar, que também no SL, deparamo-nos com trajetórias de vida que levam a experimentação para além das fronteiras deste mundo virtual, ainda que a "passagem ao real" não apareça em nosso contexto de pesquisa como mandatória.

A fim de examinar melhor esses processos de metamorfoses e transformações, sobretudo aqueles relacionados à transgeneridade dos e das avatares, iniciamos no Second Life, em 2016, trabalho de campo consistindo em acompanhar especificamente perfis de residentes, que se declaram publicamente transgêneros e frequentam grupos, no próprio SL, de apoio e de formas de sociabilidades, como festas, encontros, além de dedicados também às discussões sobre as diferentes formas de experiências da transgeneridade naquele mundo e na RL. Uma descoberta importante, ao começar a frequentar esses grupos, participando de suas reuniões, encontros e mantendo conversas pelo chat, é que muitos relatam ser transgêneros apenas na SL, portanto, nem sempre carregando uma condição trans na vida off-line. Por isso mesmo, tornou-se importante segui-los em outras plataformas digitais, particularmente no Flickr e no Tumblr, para observar se, mesmo quando usam o perfil de seus avatares, a questão da transgeneridade aparece.

Um dos grupos do SL no Flickr, no qual estivemos inseridas durante a pesquisa, tem a discussão de gênero como central. $O$ grupo foi criado em janeiro de 2009 e conta atualmente com 495 participantes. Nele, avatares do SL que participam da sociabilidade no Flickr tanto postam imagens relacionadas com gênero no mundo virtual, quanto usam o espaço de fórum de discussão do grupo para debater questões relacionadas ou divulgar eventos. A proposta do grupo provoca os seus participantes a pensar no que significa ser "masculino" ou "feminino" num mundo virtual, e sobre como avatares expressam gênero.

O criador do grupo conta ter nascido intersex na sua real life, tendo sido designada a ele uma identidade feminina ao nascer, e tendo ele transicionado ao gênero masculino nos últimos anos. Ele conta que, a partir de 2007, tem vivido o que chama de uma "odisseia de gênero", que diz respeito tanto a sua 
transição FTM (female to male) quanto à transição MTF (male to female) de sua companheira, esposa no SL desde 2007 e esposa na RL desde 2009.

Seu Flickr é bastante diferente da maioria dos Flickrs dos avatares do Second Life, pois está repleto de fotografias suas, reais, de sua família e amigos. A mistura entre SL e RL, no caso deste interlocutor, é bastante marcante. No SL, ele possui três avatares principais; um, que define como masculino, uma, que define como feminina e outro, que define como intersex. Seu avatar intersex é tido por ele como seu avatar principal, e foi ele quem primeiramente conhecemos, quando de nossa experiência de pesquisa em um ambiente pós-apocalíptico de jogo/RPG no SL chamado The Wastelands, onde vivemos e pesquisamos por alguns meses, no ano de 2011. Embora com os três ele frequente ambientes relacionados à ficção científica no SL, dentre os seus três avatares, é seu avatar intersex o que mais flerta, e o faz muito seguidamente, com outras condições “inter", incorporando elementos não-humanos, seja de outras espécies animais (asas, tentáculos, chifres) quanto maquínicos (membros mecânicos, olhos com laser etc.).

Nosso trânsito por outras plataformas, de início percorrendo trajetos semelhantes aos de nossos interlocutores no SL, levou-nos a refletir sobre os tipos de ação ou agência que cada uma dessas plataformas produz, realiza e promove nesses processos de transição, transformação e subjetivação, levando-se em conta o fato de que todas as plataformas mencionadas serem muito utilizadas, também por outros usuários (pelo menos no Brasil) LGBTQI. Considerou-se pertinente manter as observações em dois níveis, ou seja, continuar a seguir os perfis em cada uma das plataformas em separado, para, em seguida, fazer comparações entre elas: Facebook, Flickr, SL, Tumblr e Youtube. No Facebook, a existência de muitos fóruns e grupos facilitou a busca de perfis para acompanhar e conversar. O mesmo foi feito nas demais plataformas, e esses novos levantamentos mudaram bastante as percepções e ideias iniciais a respeito dos usos e das apropriações feitas por estes sujeitos das plataformas digitais.

Deparamo-nos, assim, com a grande quantidade de relatos, depoimentos, testemunhos postados por pessoas transgêneras, relacionadas ou não com o SL, e com o igualmente impressionante efeito multiplicador que elas possuem, e como agem em relação às pessoas, transgêneras ou não. Tal efeito multiplicador permite pensar, conforme sugerimos a seguir, que não se pode conceber as identidades transgêneras ignorando a participação das plataformas nos processos de transição, da mesma forma que não se pode reduzi-las apenas às transformações corporais, físicas, mas, também, incluir neste "regime de self" outras competências e equipamentos acessíveis através dos usos das 
plataformas digitais, e que passam a ter uma importância fundamental, tanto pela aquisição de um capital mecatrônico propriamente dito, mas, também, pela aquisição de um capital simbólico, advindo das interações nesses circuitos de trocas.

Argumentamos, assim, que essas identidades são também efeitos e resultados das agências e das lógicas estruturantes dessas plataformas, em decorrência dos modos de usos e engajamentos que elas engendram. Assim, as distintas plataformas digitais usadas, não são meros suportes onde se expressa algo que está se construindo em "outro" lugar, não são meras coadjuvantes no processo de produção dessas identidades, mas, igualmente, protagonistas, "actantes" (Ingold, 2011; Latour, 2012), em posição simétrica aos demais operadores (hormônios, próteses, terapias psi, cirurgias, vestuário, acessórios, objetos etc.) mobilizados na realização das transformações necessárias.

\section{Produzindo visibilidades e produzindo sujeitos}

A quantidade de conteúdo a respeito dessas transições de gênero, uma vez que nos deslocamos do SL para a observação de outras plataformas, levou a um questionamento acerca da precedência do off-line na produção das identidades transgêneras, bem como das muitas escolhas e decisões tomadas em relação às transformações corporais. Mais, ainda, uma pergunta se impôs: até que ponto as transformações decorrem todas de um projeto, de decisões e escolhas tomadas anteriormente a todo o processo de subjetivação ocorrido na rede e que passa pelas relações de engajamento com as plataformas digitais e trocas com outros sujeitos transgêneros? Em suma, o acompanhamento sistemático desses perfis pela rede tem levado à consideração de que a cultura digital, de muitas formas, tornou-se e vem se tornando um fator determinante para e na produção das identidades contemporâneas, inclusive identidades transgêneras e, portanto, acontecendo entre pessoas que, acima de tudo, se percebem como "nativas" da internet e de muitos modos se converteram subjetivamente aos modos de existência que ela engendra.

Em relação ao Youtube, observamos perfis de Youtubers transgêneros, a maioria deles dedicados aos registros de seus respectivos processos de "transição", MTF (male to female) ou FTM (female to male) e, nos quais, a intenção é relatar as etapas das transformações/metamorfoses corporais resultantes da ingestão de hormônios e outras substâncias, além de procedimentos cirúrgicos, combinados com o uso de certos objetos (roupas, acessórios e maquiagem), que, segundo eles são tomados e assumidos como operadores decisivos para marcarem tais "transições". 
Ávila (2014), em sua tese de doutorado, documenta o crescimento do uso das mídias digitais como espaço de visibilização e troca de informações sobre transgeneridade, especialmente entre homens trans. De acordo com ela:

De 2010 até fevereiro de 2012, houve um aumento no número de sites, blogs, canais do YouTube direcionados para transhomens. Em 2010, havia apenas um site, dois blogs e três canais no YouTube. Em 2012, encontrei oito blogs e quatorze canais do YouTube. Surgiram também vários grupos de transhomens na rede social Facebook (Ávila, 2014, p. 139).

A autora nos mostra a centralidade dos espaços on-line (blogs, vlogs, fóruns, grupos e páginas em redes sociais) na troca de informações, encontros e formação de grupos de apoio mútuo entre transhomens. Mais além, o trabalho de Ávila (2014) é um dos poucos que encontramos a tomar seriamente a questão sobre o que o uso das plataformas digitais está produzindo, não apenas tornando visível. Em seus dados de pesquisa, são narradas uma série de trajetórias de transhomens de diferentes idades, que relatam a "descoberta" ou a "aproximação" da transgeneridade acontecendo a partir do contato com informações, outras narrativas de vida ou produtos mediáticos acessados via internet. Tal perspectiva é inspiradora porque, na nossa visão, a maioria das abordagens interseccionais sobre gênero e sexualidade não têm privilegiado perspectivas que destaquem as relações entre humanos e coisas (não-humanos) e que incorpore as relações propriamente sociotécnicas, abstraindo de seu horizonte de pesquisa quaisquer agências maquínicas desenvolvidas entre humanos, máquinas e plataformas (softwares).

Neste sentido, falar de visibilidade e empoderamento não implica apenas a capacidade de se reunirem em grupos on-line para debaterem pautas e ações da militância LGBTQI, mas o fato mesmo de "produzirem e habitarem" (Ingold, 2011) estes ambientes virtuais e desenvolverem, com eles, relações de profundo engajamento, levando em conta que esses sujeitos efetivamente migram, deslocam-se e passam a habitar essas plataformas e não apenas "consumirem-nas". Na maior parte dos casos, o que se pode observar é que a produção desta identidade e de muitas outras exige, igualmente, produzir um modo de existência nestas plataformas, já que é preciso "produzir" também estes espaços de compartilhamento, onde permanecem conectados muitas horas, não apenas para discutirem sua condição, mas para viverem nele sua condição como transgêneros/as.

Mais ainda, não se trata de pensar gênero em termos essencialistas, muito menos como algo estável, do tipo "nasci assim, fui sempre assim". Mesmo na construção nativa - e ela, de fato, encontra-se presente em muitas 
narrativas - esta frase precisa ser examinada, na medida em que constatase, empiricamente, a existência de um processo, isto é, de um "movimento", de um "deslocamento" entre uma situação inicial de desconfiança sobre seu próprio gênero designado off-line, e a produção e realização plena de uma identidade transgênera, em termos corporais e subjetivos, a partir de um modo de existência específico, que cada vez mais inclui possuir, também uma vida digital, o que significa dizer que trata-se, também, de usar diferentes plataformas, circular por elas, como se faz na cidade que habitamos quando temos nossos circuitos e hábitos de frequentação.

Nesse sentido, como sugere Preciado (2014):

[...] talvez, se as hipóteses do chamado 'construtivismo de gênero', foram aceitas sem produzir transformações políticas significativas, pode ser exatamente porque tal construtivismo não só mantém, como depende de uma distinção entre sexo e gênero que torne efetiva a oposição tradicional entre cultura e natureza e, por extensão, entre tecnologia e natureza (Preciado, 2014, p. 94).

Se argumentamos que, se as identidades transgêneras ou outras são "produções" (Ingold, 2011), significa dizer que são necessários muitos investimentos da parte destes sujeitos, que vão desde a aquisição de um capital biomédico e biopolítico (Rose, 2011), o que implica acesso a informações que, muitas vezes, não se encontram disponíveis de forma imediata, mas dependem de buscas, pesquisas e que não são feitas solitariamente, mas necessitam de redes, grupos de discussão para trocas e compartilhamentos, da mesma forma que exige troca de experiências para se tomar decisões e fazer escolhas, que envolvem procedimentos mais radicais, tais como hormônios, cirurgias, próteses, etc., que provocam modificações visíveis e profundas em seus próprios corpos e subjetividades, quanto em outros contextos de suas vidas, como a mudança de identidade civil, por exemplo. Tudo isso produz, também, um acúmulo de experiências que precisam ser circuladas e compartilhadas. A rede não é apenas um lugar de comunicação e troca de informação, mas um espaço onde se habita, vive-se e, neste caso, como qualquer modo de existência, requer aquisição de competências que exigem não só a "produção" desta habitação e forma de habitar, o que inclui criar também um regime de self ou um second self para se viver neles.

Em consequência desta perspectiva, a questão importante passou a ser, então similar àquela mencionada por Latour, quando fez a analogia com um supermercado imaginário, onde é possível vermos, tanto gôndolas cheias de vínculos e identidades sociais, quanto "alas exibindo conexões 'materiais', 
'biológicas', 'psicológicas' e 'econômicas"” (Latour, 2012, p. 99). Como o autor assinala, a teoria ator-rede "não designa com esses termos um domínio da realidade ou um item especial; é antes o nome de um movimento, um deslocamento, uma transformação, uma translação, um registro" (Latour, 2012, p. 99). Neste contexto, as plataformas digitais, além de serem as alas e gôndolas, onde se promovem as múltiplas associações e conexões entre os demais itens e operadores das transformações, também promovem essas múltiplas conexões e associações.

Esse tipo de discussão leva, mais uma vez, para a problemática das infiltrações entre o on e o off. Com frequência, como no já bastante conhecido trabalho de Miller e Slater (2004), em termos metodológicos, vimos sublinhada a impossibilidade de separá-los como domínios substancialmente diferenciados. $\mathrm{Na}$ maior parte das vezes que tal argumento é utilizado, no entanto, fala-se, sobretudo, da impossibilidade de desconsiderar a existência do on sem o off, e da impossibilidade de se compreender nossos sujeitos de pesquisa, no on, sem considerar o que carregam consigo, do off para o on: pertencimentos de classe, grupo etário, estilo de vida, gênero, nacionalidade, grupo étnico, etc. Enfatizamos que tal articulação toma proporções diferenciadas, dependendo do contexto estudado, e que ela não pode, nunca, ser pensada a priori. Consideramos que na discussão sobre os trânsitos, limites e escorregamentos entre on e off, precisa ser cada vez mais incorporada também a perspectiva simétrica, mas oposta. Se convém sempre estar atento ao que o "aqui" produz "lá", é igualmente pertinente considerar o que o "lá" produz "aqui", sem tomar como dado que um desses lócus seja simples reflexo do outro.

\section{Considerações finais}

A partir de nossa pesquisa etnográfica no mundo virtual Second Life e seus deslocamentos e transbordamentos para outras plataformas digitais on-line, apresentamos algumas reflexões sobre "regimes de self" contemporâneos, especialmente no que concerne a experimentações de si relacionadas ao gênero e à sexualidade. Argumentamos, aqui, que tais regimes de self são construídos a partir da participação, usos e apropriações de objetos e substâncias, cujos pressupostos sejam eminentemente tecnológicos, com propósito de transformação pessoal, tais como ingestão de substâncias (dietas especiais, medicamentos, suplementos, hormônios), artefatos (acessórios, aparelhos, objetos, roupas), cirurgias (próteses) e, sobretudo, as plataformas digitais.

Quanto a estas últimas, a internet vem promovendo uma verdadeira revolução em nossos entendimentos sobre "nós mesmos", paralelamente à promoção de novos processos de subjetivação, dando origem a novos 
discursos e "narrativas de si", através dos diferentes modos de engajamento com as plataformas digitais. Mas mais do que narrar e compartilhar dramas sociais e estigmas experimentados na vida off-line, o que se observa nos ambientes digitais são os usos e apropriações criativas que esses sujeitos fazem do ciberespaço, para se reinventarem e construírem novas formas de apresentação de si, através da experimentação e da relação lúdica e estética com essas plataformas.

Finalmente, sabemos que não se vive apenas ali e, neste caso, é possível dizer que este modo de existência digital, se não é necessariamente outro self, não é mais, de forma alguma, autorregulado e unitário. Para dar conta de todas as vicissitudes, ele requer um processo intenso de subjetivação, cujo resultado são as "internalidades", ou aquilo que Nikolas Rose (2011, p. 60) chamou, inspirando-se em Deleuze, de "dobras" ou "pregas", que "incorporam sem totalizar, internalizam sem unificar; de maneira descontínua, tecem-se na forma de pregas, produzindo superfícies, espaços, fluxos e relações" (Rose, 2011, p. 61). A melhor ilustração deste conceito de dobras pode ser encontrada no Second Life, se pensarmos que avatares podem ser pensados como sendo espécies de "dobras" ou "pregas" objetificadas que um mesmo usuário pode possuir, como se fossem seus diferentes territórios existenciais naquele mundo, algo que é, ao mesmo tempo, maravilhoso, inquietante e estranho.

\section{Referências}

ÁVILA, Simone. FTM, transhomem, homem trans, trans, homem: a emergência de transmasculinidades no Brasil contemporâneo. Florianópolis, 2014. Tese de doutorado. Pós-graduação Interdisciplinar em Ciências Humanas, Universidade Federal de Santa Catarina.

BELELI, Iara; MISKOLCI, Richard. Apresentação (dossiê Percursos digitais, corpos, desejos, visibilidades). Cadernos Pagu, n. 44, p. 7-11, $2015<10.1590 / 1809-$ 4449201500440007>.

ESCOBAR, Arturo. Welcome to cyberia: notes on the anthropology of cyberculture. Current Anthropology, v. 35, n. 3, p. 211-231, 1994.

FACCHINI, Regina; MACHADO, Sara Rosseti. "Praticamos SM, repudiamos agressão": classificações, redes e organização comunitária em torno do BDSM no contexto brasileiro. Sexualidad, Salud y Sociedad, n. 14, p. 195-228, $2013<10.1590$ / S1984-64872013000200014>.

GOMES, Laura Graziela; LEITÃO, Débora Krischke. Estar e não estar lá, eis a questão: pesquisa etnográfica no Second Life. Cronos, v. 12, n. 1, p. 23-38, 2011.

HINE, Christine. Virtual ethnography. Londres: Sage Publications, 2000.

HINE, Christine. Ethnography for the internet: embedded, embodied and everyday. Huntingdon, GBR: Bloomsbury Publishing, 2015. 
INGOLD, Tim. Estar vivo: ensaios sobre movimento, conhecimento e descrição. Petrópolis: Editora Vozes, 2011.

LATOUR, Bruno. Reagregando o social. Salvador: Editora Ufba, 2012.

LUPTON, Deborah. Digital sociology. New York: Routledge, 2015.

MILLER, Daniel; HORST, Heather (orgs.). Digital Anthropology. Londres: Berg, 2012.

MILLER, Daniel; SLATER, Don. Etnografia on e off-line: cybercafés em Trinidad. Horizontes Antropológicos, n. 21, p. 41-65, $2004<10.1590 / \mathrm{S} 0104-$ $71832004000100003>$.

MISKOLCI, Richard. O armário ampliado: notas sobre sociabilidade homoerótica na era da internet. Gênero, v. 9, n. 2, p. 171-190, $2009<10.22409 /$ rg.v9i2.88>.

MISKOLCI, Richard. Sociologia Digital: notas sobre pesquisa na era da conectividade. Contemporânea, v. 6, n. 2, p. 275-297, $2016<10.4322 / 2316-1329.014>$.

MISKOLCI, Richard. Desejos digitais. Belo Horizonte: Autêntica Editora, 2017.

PARREIRAS, Carolina. Sexualidades no ponto.com: espaços e (homo) sexualidades a partir de uma comunidade on-line. Campinas, 2008. Dissertação de mestrado em Antropologia Social, Instituto de Filosofia e Ciências Humanas, Universidade Estadual de Campinas.

PRECIADO, Beatriz. Manifesto contrassexual. São Paulo: N-1 Edições, 2014.

ROSE, Nikolas. Inventando nossos selfs. Psicologia, poder e subjetividade. Petrópolis: Editora Vozes, 2011.

VENCATO, Anna Paula. Negociando desejos e fantasias: corpo, gênero, sexualidade e subjetividade em homens que praticam crossdressing. In: Maria Elvira Díaz-Benitez; Carlos Eduardo Figari (orgs.). Prazeres dissidentes. Rio de Janeiro, Clam, 2009.

VENCATO, Anna Paula. Sapos e princesas: prazer e segredo entre praticantes de crossdressing no Brasil. São Paulo, Annablume, 2013.

VENCATO, Anna Paula. Entre "reais" e "virtuais": noções sobre risco e verdade em um clube brasileiro para crossdressers. Cadernos Pagu, n. 44, p. 367-390, 2015 $<10.1590 / 1809-4449201500440367>$.

VIVEIROS DE CASTRO, Eduardo. O nativo relativo. Mana. v. 8, n. 1, p. 113-148, $2002<10.1590 / \mathrm{S} 0104-93132002000100005>$.

ZILLI, Bruno. A perversão domesticada. Rio de Janeiro, 2007. Dissertação de mestrado em Saúde Coletiva, Universidade do Estado do Rio de Janeiro.

Recebido em: 31 ago. 2017

Aprovado em: 16 fev. 2018

Autora correspondente:

Débora Krischke Leitão

Programa de Pós-Graduação em Ciências Sociais

Universidade Federal de Santa Maria

Av. Roraima, 1000, prédio 74, CCSH, 2ำ andar, sala 2205

Campus Universitário - Camobi

97105-900 Santa Maria, RS, Brasil 